\title{
DESIGN OF THE HEAT PIPE HELIUM GREENHOUSE FOR THE EFFECTIVE USE OF THE SOIL HEAT
}

\author{
Amirhan Matyakubov ${ }^{1, *}$, Kakageldi Saryyev ${ }^{1}$, Serdar Nazarov $^{1}$, and Gulshat Gurbanova ${ }^{1}$ \\ ${ }^{1}$ State Energy Institute of Turkmenistan, st Bayramhan 62, c. Mary 745400, Turkmenistan
}

\begin{abstract}
This scientific work presents the results of scientific research on the use and accumulation of solar energy for heat supply of a solar greenhouse. For a real assessment of the problem, the following information can be cited as an example: in a greenhouse with a total area of $234 \mathrm{~m}^{2}$ covered with polyethylene film must be installed, on the average, with 6-8 furnaces to provide a certain amount of warm air. One furnace consumes about $2448 \mathrm{~m}^{3} / \mathrm{h}$ of natural gas for four months, and during this time $8.6 \mathrm{~kg}$ of carbon dioxide $\left(\mathrm{CO}_{2}\right)$ is emitted from one furnace. As a result, taking into account the payment for the consumption of natural gas, the problem of the cost of the obtained products, energy conservation, and also environmental protection is very urgent. To solve this problem, a solar greenhouse with an additional heating chamber was constructed at the research site of the State Energy Institute of Turkmenistan. In this structure, excess of solar and heat energy of the soil was accumulated in mountain stones, and carbon dioxide that emits soil (horse manure was used as a soil) was used to feed the Chlorella vulgaris suspension grown in the photobioreactor, which in its turn had a beneficial effect on its cultivation. To transfer heated air from the additional heating chamber to the solar greenhouse and the accumulated thermal energy of the soil, polyethylene pipes with holes were used. Due to the use of the heat capacity of the materials (rock stones), a two-layer coating of the structure, compaction of the northern side with wool and accumulated heat energy, it was possible to achieve a positive temperature in the solar greenhouse in the minus environmental values. The technologies and processes considered in this research are mainly renewable energies and technical (chemical reactions) solutions such as photovoltaic (PV) modules, phase exchange material (PCM), underground heat storage technologies, energy efficient heat pumps and facade materials for the better heat insulation. The obtained results of the research work can be applied in solar greenhouses, the construction of which is planned in the areas remote from the central power supply network, since heat supply is carried out using solar energy and electric lighting is implemented due to the solar panels with a built-in LED lamp. It should be borne in mind that the intensity of solar radiation on the territory of Turkmenistan fluctuates in the range of 700-800 W/m2, which indicates the huge possibilities of using solar energy.
\end{abstract}

\section{Introduction}

One of the global challenges for the developing countries is sustainable agriculture, which, in its turn, entails three main aspects: energy efficiency, environmental impact and profitability.

As the population grows, higher yields and higher profitability are required. A greenhouse is used to increase yields and control growth in any climate, but at the same time it is one of the most energy intensive sectors of agriculture. The greenhouse is one of the most profitable sectors as it has a very high power output, which is 10-20 times that of horticulture [1].

High yields require significant capital investments, labor costs, fertilizers and energy costs for heating and lighting. Taking into account the constant world growth in the cost of energy (for oil, gas, coal, etc.), as well as prices for the main material used in the greenhouse polyethylene film, it is necessary to adhere to the rational use of electrical and heat energy in the agricultural sector. An alternative solution to this problem is the transition to the use of solar greenhouses.

All modern greenhouses are equipped with various sensors (temperature, humidity, etc.) and additional heat sources (gas and electric ovens), but all these additional elements lead to an increase in the cost of the greenhouse, and later on the resulting products, which in its turn, leads to a decrease in demand.

The purpose of this scientific work is to find the optimal solution for heating the greenhouse using solar energy in the conditions of Turkmenistan, accumulating excess of heat energy during the day, thereby regulating the temperature inside the solar greenhouse, and at night to get the reverse process.

In the course of work in the solar greenhouse, all heat losses were minimized, and the lack of heat energy was compensated for by three methods, due to its own penetration of the intensity of sunlight, due to heated

\footnotetext{
* Corresponding author: amirhan31071989@mail.ru
} 
warm air from the heating chamber and due to the heat energy of the soil of the heating chamber.

Warm air is sucked out of the heating chamber and passes along the entire perimeter of the greenhouse, thereby ensuring uniform heating of the soil, and excess of heat energy escapes from the heat pipe near the door, which, in its turn, minimizes heat losses.

The solar greenhouse is covered with a double-layer polyethylene film, the distance between the films is 10 $\mathrm{cm}$, this allows you to get the so-called "Thermos" effect, and the northern side is compacted with wool, which, in its turn, makes it possible to minimize heat losses and protect the seedlings from frost during subzero temperatures environment.

As an additional source of heat, an additional heating chamber is built on the front side, the roof of which is made of glass at an angle of 36 degrees to the south, which, in its turn, allows increasing the penetration of sunlight, thereby obtaining a higher temperature that differs from the environment and from the solarium. A fan is installed in the heating chamber to transfer warm air to the solar greenhouse through heat polyethylene pipes. The beginning of the heat pipes is laid in the heating chamber, the end in the solar greenhouse, and the main part is laid under the ground in the solar greenhouse.

The first steps towards regulation and accumulation of temperature were outlined in the works [1], and in [2] the results of scientific research on heat supply to the greenhouse with the help of a boiler are given, and several works are also devoted in [3] where heat supply is provided by the heat of the exhaust flue gases.

In mathematical modeling of a greenhouse, the entire greenhouse structure can be considered as solar collectors, and its characteristics are described in a similar way using a single energy balance equation, in which the main parameters are the intensity of solar radiation and the total energy loss factor [4-6].

The author [7] presented a dynamic greenhouse model based on primary boundary conditions and used the soil's ability to store heat. The system, divided into 4 sections, includes: soil, plants (seedlings), indoor air and greenhouse cover. Then the heat and mass balance between the main elements is calculated. The results showed that there is a significant relationship between indoor humidity and outdoor temperature and solar radiation intensity.

Humidity can increase at night with an increase in external temperature and with a sharp decrease in solar radiation (with a change in the atmospheric mass, (AM)). Also, the internal temperature and humidity decrease day and night when the ventilation system is in operation. At night, when the heating system was operating, the air temperature increased and the relative humidity decreased. The authors of [8] presented a mathematical model for assessing temperature and humidity in a solar greenhouse. They developed a mathematical model based on active and passive forms of heat storage. To reduce heat loss at night, thermal insulation was applied between the arches, two-layer transparent plastic covers were installed. The results showed that there is a difference between simulation and experimental verification. The developed model makes it possible to predict energy consumption in solar greenhouses. The time step up to $900 \mathrm{~s}$ creates some problems in modeling. Thus, they came to the conclusion that the optimal accuracy should be between 300 and $600 \mathrm{~s}$. In another research, energy and mass transfer (phase transition) were analyzed in a typical winter greenhouse [9].

To study the effectiveness of various energy conservation measures applied, the authors of [10] developed a mathematical model to approximate a set of design features for a greenhouse in India. The model was used to study the effect of different greenhouse shapes, orientation and different applied energy saving measures (such as heat insulation of the north wall, double glazing of walls and night curtains) on the heat energy consumption of the greenhouse under environmental conditions (cold and sunny day), measuring 12 x $200 \mathrm{~m}$, located in Delhi. All these scientific studies made it possible to provide greenhouses with thermal energy, and thereby cover the cost of heat supply.

\section{Materials and methods}

In order to investigate the possibility of heating the greenhouse through heat pipelines, a helium greenhouse with an area of $24 \mathrm{~m}^{2}$, and a volume of $54.4 \mathrm{~m}^{3}$ and an additional heat source with an inclination angle of $36^{\circ}$ degrees covered with glass cover with an area of $7.5 \mathrm{~m}^{2}$, with a volume of $7.5 \mathrm{~m}^{3}$ were installed in the State Energy Institute of Turkmenistan. The drawing of the helium greenhouse is shown in Figure 1 below.

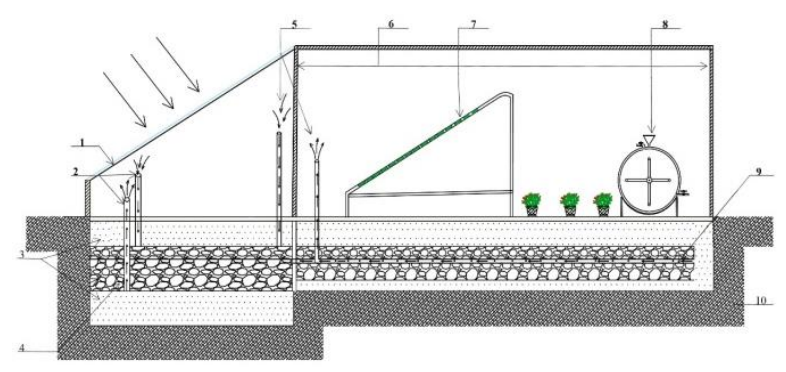

Fig. 1. General drawing of the helium greenhouse: 1 - outer glass cover of the heating chamber; 2 - inlet and outlet of the heat pipe at the bottom of the heating chamber; 3 - course layer; 4 - stone layer; 5 - entrance and exit of heat pipe at the bottom of the greenhouse; 6 - woolly wall; 7- photobioreactor; 8 - biogas plant; 9 - heat pipes; 10 - soil layer.

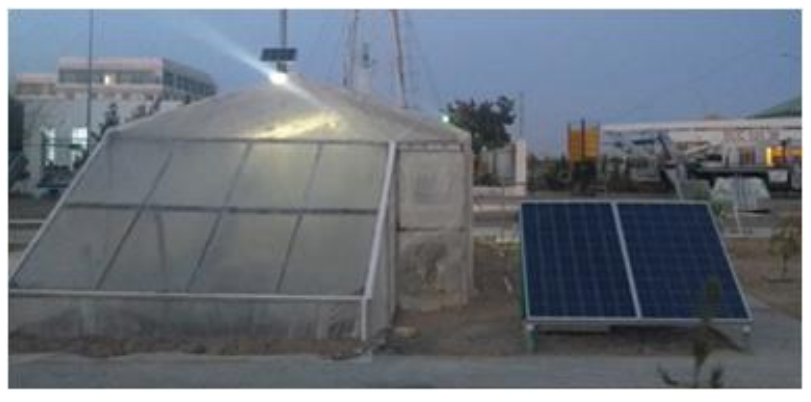

Fig. 2. General appearance of the helium greenhouse. 
The designed helium greenhouse was aimed at ensuring a normal level of heat in the greenhouse by using soil heat. Inside the helium greenhouse, biogas plant with the volume equal to $1000 l$, photobioreactors with the volume equal to $120 l$ and seedlings of several plants were placed. The classified carbon dioxide chlorella vulgaris, which is grown in a photobioreactor through a special compressor was also used to feed the plants. All compressors in the greenhouse were fed through a photovoltaic solar panel with a nominal power of $500 \mathrm{~W}$ (Figure 2)[11-13].

The total depth of the helium greenhouse is equal to $800 \mathrm{~mm}$, the bottom of which is covered with soil with a polyethylene film. Over it, manure was placed as a 200 $\mathrm{mm}$-thick-heat source, and $200 \mathrm{~mm}$ thick rocks were placed to collect thermal energy. Heat pipes were also installed over those rocks. The heat pipe starts in an additional heating chamber and is curved and placed in the lower part of the greenhouse, and its exit ends in the greenhouse. Heat pipes are made of polyethylene pipes with a diameter of $50 \mathrm{~mm}$, and holes are made in the underground part with a diameter of $10 \mathrm{~mm}$, the distance of which is $30 \mathrm{~cm}$. With the help of these holes, the greenhouse was provided through heat pipes from the stones.

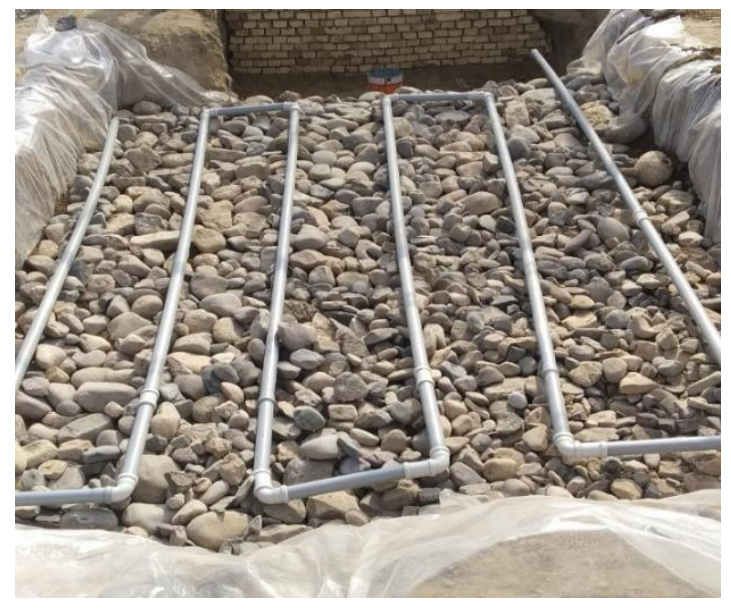

Fig. 3. Placement of heat pipelines in a helium greenhouse.

$200 \mathrm{~mm}$ thick rocks were also placed over the heat pipelines, and the rest of the helium greenhouse was also laid with $200 \mathrm{~mm}$ thick combination of sand and manure.

The amount of heat required to heat the greenhouse is determined by the following formula [14-17]:

$$
Q=k_{1} \cdot k_{2} \cdot S \cdot\left(T_{1}-T_{2}\right)
$$

where $k_{I}$ is the infiltration coefficient, $k_{I}=1.25 ; T_{I}-$ normal temperature inside the greenhouse, which should be $+18^{\circ} \mathrm{C} ; T_{2}-$ is the minimum air temperature, which is also assumed to be nearly $-9.4{ }^{\circ} \mathrm{C}$ for Mary province (in the literature and technical documents); $k_{2}$ - thermal conductivity coefficient, which can be determined by the following table 1.
Table 1. Heat transfer coefficient depending on the material of the greenhouse surface.

\begin{tabular}{|c|c|}
\hline Type of material & Coefficient value \\
\hline Single layer glass & 6.4 \\
\hline Double layer glass & 3.3 \\
\hline $\begin{array}{c}\text { Single-layer polyethylene film (dry } \\
\text { layer) }\end{array}$ & 10 \\
\hline $\begin{array}{c}\text { Single layer polyethylene film } \\
\text { (condensate drops in layer) }\end{array}$ & 7.5 \\
\hline Two-layer polyethylene film (dry layer) & 5.8 \\
\hline $\begin{array}{c}\text { Double layer polyethylene film } \\
\text { (condensate drops in layer) }\end{array}$ & 4.6 \\
\hline Concrete socle & 2.0 \\
\hline
\end{tabular}

We are performing calculations for the helium greenhouse, which is located in the research area of the Renewable Energy Sources scientific-production center of the State Energy Institute of Turkmenistan.

Calculation of the heat losses in a solar greenhouse with an area of $24 \mathrm{~m}^{2}$.

Initial data:

$\mathrm{T}_{1}=+18{ }^{\circ} \mathrm{C}$ $\left.3^{\circ} \mathrm{C}\right)$

$\mathrm{T}_{2}=3$ (the average air temperature in November was

$Q_{\text {heat losses }}=4.6 \cdot 1.5 \cdot 24 \cdot(18-3)=2484 \mathrm{~W}=2.5 \mathrm{~kW}$

$Q_{\text {heat losses }} \cdot k_{l}=2.5 \cdot 1.25=3.125 \mathrm{~kW}$.

The required heat capacity is determined

$Q=k_{1} \quad \cdot k_{2} \cdot S \cdot\left(T_{1}-T_{2}\right)=1.25 \cdot 4.6 \cdot 6.4 \cdot 24 \cdot(18-(-$

9.4) $=24199.7 \mathrm{~W} Q=24.2 \mathrm{~kW}$

Thus, the amount of heat required for the greenhouse is $24.2 \mathrm{~kW}$.

A heat balance equation for incoming energy is drawn up, which consists of two components, i.e.

-The amount of heat supplied through the ventilation air, which is calculated by the following expression

$$
Q_{a i r}=G \cdot C p \cdot\left(T_{1}-T_{2}\right)
$$

where $G$ - mass consumption of air from the fan; $\mathrm{kg} / \mathrm{hour}$

$C_{p}$ - specific heat capacity of air at different temperatures, $0.241 \mathrm{~J} / \mathrm{kg} \cdot \mathrm{K}$

$T_{1}$ - the temperature at the output of the heat pipe, ${ }^{\circ} \mathrm{C}$ $T_{2}$ - the temperature at the inlet of the heat pipe, ${ }^{\circ} \mathrm{C}$

-Mass air consumption from the fan is determined by the following expression

$$
G=V \cdot \rho
$$

where $V$ - fan performance, Tidar RQA 12038HSL 220VAC series $170 \mathrm{~m}^{3} / \mathrm{h}$ [18]

$\rho$-air density at different temperatures, $\mathrm{kg} / \mathrm{m}^{3}$

The amount of heat transmitted to the greenhouse by solar radiation is calculated by the following expression:

$$
Q_{\text {rad }}=\eta \cdot I_{c} \cdot F_{\text {rad }} \cdot \tau
$$

where: $\eta$ - the efficiency of the heat conversion of the beam equal to $\eta=0.7$; Ic - solar radiation intensity, $\mathrm{W} / \mathrm{m}^{2} ; \tau$ - the heat transfer coefficient, for a polyethylene film, the coefficient value is assumed to be 0.35 . It is estimated that solar radiation reaches half of the roof area: 


$$
F_{r a d}=b \cdot L_{k}
$$

where $L_{k}$ - typical roof dimensions, $6 \mathrm{~m}$

$b$ - the length of the roof, $4.8 \mathrm{~m}$.

\section{Results}

The results of measurements and calculations for the case of heating with the help of heat pipes are given in table 2 .

Table 2. Results of measurement and calculation of parameters.

\begin{tabular}{|c|c|c|c|c|c|c|c|}
\hline $\begin{array}{c}\text { Time, } \\
h\end{array}$ & $\begin{array}{c}\Delta \mathrm{T}, \\
K\end{array}$ & $\begin{array}{c}\rho, \\
\mathrm{kg} / \mathrm{m}^{3}\end{array}$ & $\begin{array}{c}\mathrm{G}, \\
\mathrm{kg} / \mathrm{h}\end{array}$ & Qair, $W$ & $\begin{array}{c}\mathrm{I}_{\mathrm{c}}, \\
W / \mathrm{m}^{2}\end{array}$ & Qrad, $W$ & Qbal, $W$ \\
\hline $08^{00}$ & 11 & 1.2284 & 212.5 & 654.68 & 20.4 & 81 & 735.68 \\
\hline $10^{00}$ & 15.2 & 1.226 & 208.42 & 887.4 & 278 & 2046.24 & 2933.64 \\
\hline $12^{00}$ & 12.4 & 1.235 & 209.95 & 730 & 450 & 3034.08 & 3764.08 \\
\hline $14^{00}$ & 14.9 & 1.224 & 208.08 & 868.4 & 476 & 2829.6 & 1340 \\
\hline $16^{00}$ & 7.3 & 1.257 & 213.69 & 437 & 266 & 809.4 & 1246.4 \\
\hline $18^{00}$ & 12 & 1.237 & 210.29 & 706.8 & 0 & 0 & 706.8 \\
\hline $20^{00}$ & 7 & 1.259 & 214.03 & 420 & 0 & 0 & 420 \\
\hline
\end{tabular}

In this case, the heat of the soil (manure) accumulated with the underground rocks on the basis of usual convection was transferred to the greenhouse through heat pipes, the degree of heat coming out of the heat pipelines and the relationship between the heat generated in the greenhouse are shown in figure 4 below.

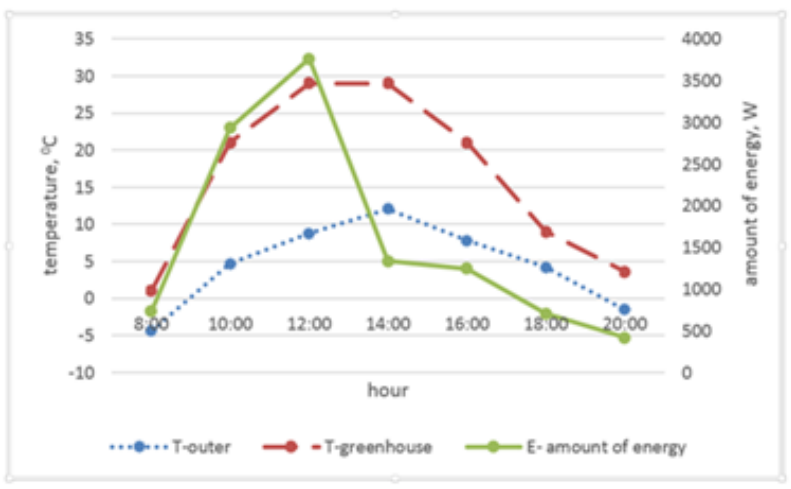

Fig. 4. Time dependence of the effect of heat supplied to the greenhouse by the underground pipeline to the heat level inside it.

As can be seen from the dependence, it allows the necessary heat to be maintained in the greenhouse by means of heat pipelines, however, when the ambient temperature has a minus sign, the heat required for the seedlings in the greenhouse is low, i.e. the outside temperature is equal to $-5^{\circ} \mathrm{C}$ at 08.00 in the morning, while the temperature inside the greenhouse is $+1{ }^{\circ} \mathrm{C}$.

2. Heating the greenhouse through the heat pipes using heat pumps.

The total depth of the heating chamber is $1,400 \mathrm{~mm}$ and a polyethylene layer is placed on the bottom layer of it. It is covered with a layer of $400 \mathrm{~mm}$ thick. $200 \mathrm{~mm}$ thick rocks were placed to collect the heat of the course. They have a stainless steel pipe with a diameter of 100 $\mathrm{mm}$ on top of it to transfer the accumulated heat into the chamber. $200 \mathrm{~mm}$ thick rocks were also placed over the heat pipe. The rest of the chamber was filled with horse manure. Because of the large amount of solar energy that falls on the camera when viewed from a flat-heated greenhouse (Figure 5), it contains a large amount of heat, in contrast to the environment.

The measurement and calculation results for the case when heating the greenhouse through the heat pipes using heat pumps are shown in Table 3.

Table 3. Results of measurement and calculation of parameters.

\begin{tabular}{|c|c|c|c|c|c|c|c|}
\hline $\begin{array}{c}\text { Time, } \\
h\end{array}$ & $\begin{array}{c}\Delta \mathrm{T}, \\
K\end{array}$ & $\begin{array}{c}\rho, \\
\mathrm{kg} \backslash \mathrm{m}^{3}\end{array}$ & $\begin{array}{c}\mathrm{G}, \\
\mathrm{kg} / \text { hour }\end{array}$ & $\begin{array}{c}\mathrm{Q}_{\text {air, }} \\
W\end{array}$ & $\begin{array}{c}\mathrm{I}_{\mathrm{c}}, \\
W / \mathrm{m}^{2}\end{array}$ & Qrad, $W$ & Qbal, $W$ \\
\hline $08^{00}$ & 14 & 1.2284 & 208.83 & 818.9 & 20,4 & 144 & 962.9 \\
\hline $10^{00}$ & 16.8 & 1.2165 & 206.805 & 973.1 & 278 & 1961.4 & 2934.5 \\
\hline $12^{00}$ & 13.4 & 1.230 & 209.3 & 784.4 & 450 & 3175.2 & 3960.6 \\
\hline $14^{00}$ & 10.7 & 1.242 & 211.14 & 632.8 & 476 & 3360 & 3992.8 \\
\hline $16^{00}$ & 6 & 1.264 & 214.88 & 361 & 266 & 1876.8 & 2237.8 \\
\hline $18^{00}$ & 10 & 1.246 & 211.82 & 593.1 & 0 & 0 & 593.1 \\
\hline
\end{tabular}

Thus, the complex was designed to heat the soil and air of the helium greenhouse through underground heat pipelines with the heat generated in the heating chamber.

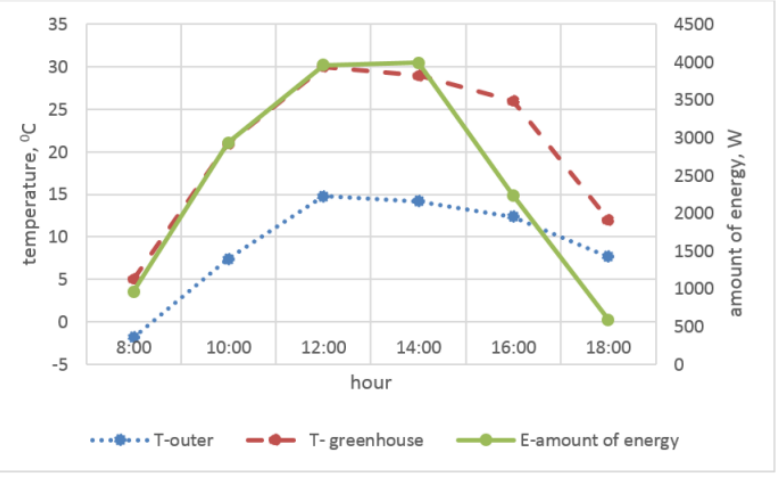

Fig. 5. The time-dependent effect of the heat supplied to the greenhouse by the heat pump through the heat pump to the heat level inside it.

As can be seen from the dependence that the use of a heat pump helps to increase the heat level inside the greenhouse to a certain extent, because it managed to maintain a temperature of $+5{ }^{\circ} \mathrm{C}$ in the greenhouse even when the outside temperature was $-2{ }^{\circ} C$, which is the same as before the heat pump was used and over time, that difference has increased.

\section{Execution of heat in the soil of the heating} chamber for heating the greenhouse.

In this method the soil heat of the heating chamber installed in front of the greenhouse was used to heat the greenhouse through the heat pumps.

The measurement and calculation results for the case when Execution of heat in the soil of the heating chamber for heating the greenhouse are shown in Table 4. 
Table 4. Results of measurement and calculation of parameters.

\begin{tabular}{|c|c|c|c|c|c|c|c|}
\hline $\mathrm{T}, h$ & $\begin{array}{c}\Delta \mathrm{T}, \\
K\end{array}$ & $\begin{array}{c}\rho, \\
k g / m^{3}\end{array}$ & $\begin{array}{c}\mathrm{G}, \\
k g / h\end{array}$ & $\mathrm{Q}_{\text {air }}, W$ & $\begin{array}{c}\mathrm{I}_{\mathrm{c}}, \\
W / m^{2}\end{array}$ & $\begin{array}{c}\text { Qrad, } \\
W\end{array}$ & $\begin{array}{c}\text { Qbal, } \\
W\end{array}$ \\
\hline 08.00 & 2 & 1.282 & 217.94 & 122.08 & 19.1 & 135 & 257.08 \\
\hline 10.00 & 14.1 & 1.228 & 208.76 & 824 & 221 & 1560 & 2374 \\
\hline 12.00 & 15.4 & 1.222 & 207.74 & 896 & 380 & 2682 & 3578.4 \\
\hline 14.00 & 14.1 & 1.228 & 208.76 & 824 & 536 & 3780 & 4604 \\
\hline 16.00 & 6.2 & 1.263 & 214.71 & 373 & 250 & 1764 & 2137 \\
\hline 18.00 & 10 & 1.246 & 211.82 & 592.8 & 0 & 0 & 592.8 \\
\hline 20.00 & 10 & 1.246 & 211.82 & 592.8 & 0 & 0 & 592.8 \\
\hline 22.00 & 10 & 1.246 & 211.82 & 592.8 & 0 & 0 & 592.8 \\
\hline 00.00 & 10.6 & 1.243 & 211.31 & 627.4 & 0 & 0 & 627.4 \\
\hline 2.00 & 12 & 1.237 & 210.29 & 706.8 & 0 & 0 & 706.8 \\
\hline 4.00 & 11.4 & 1.24 & 210.8 & 672.9 & 0 & 0 & 672.9 \\
\hline 6.00 & 10.9 & 1.242 & 211.14 & 644.5 & 0 & 0 & 644.5 \\
\hline 8.00 & 14 & 1.228 & 208.76 & 650.2 & 23 & 162.3 & 812.5 \\
\hline
\end{tabular}

The heat under the heating chamber was pumped through a special heat pump and fed to the underground heat pipelines of the helium greenhouse. In this case, the the effect of the heat amount supplied to the greenhouse on the heat level inside it is shown in Figure 6 below.

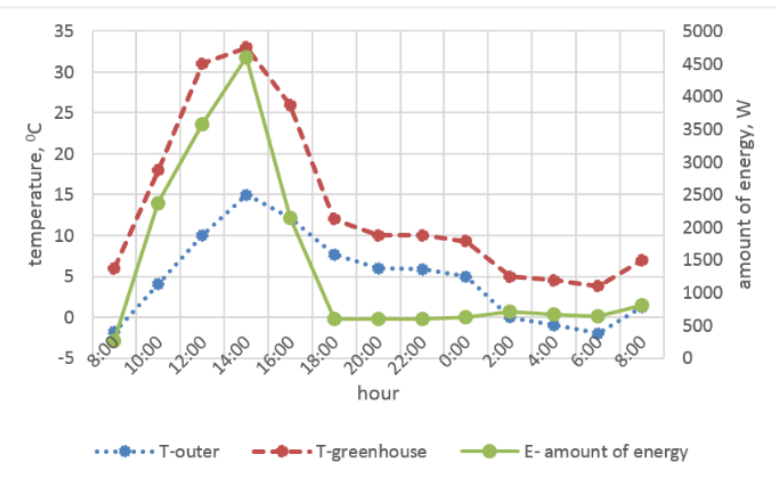

Fig. 6. Time dependence of the heat generated in the greenhouse by the use of heat in the heating chamber.

As can be seen from the dependence, the heating chamber was able to make a difference of at least $+5{ }^{\circ} \mathrm{C}$ when using the soil temperature. This suggests that it is also important to use a heating chamber with an additional heat source. As also can be seen from the dependence, the temperature inside the greenhouse in the afternoon reaches a temperature that is airy for the plants, therefore it was intended to collect the accumulated heat. The excess heat in the greenhouse during the day was transferred to the underground rocks through a heat pump, thus maintaining the normal temperature during the day in the greenhouse.

\section{Discussions}

For the design of the heat pipe helium greenhouse aimed at the effective use of the soil heat a heat chamber in the form of greenhouse with the total volume of $7.5 \mathrm{~m}^{3}$ and an area of $7.5 \mathrm{~m}^{2}$ and a helium greenhouse with an area of $24 \mathrm{~m}^{2}$ were built in the research area of the State Energy Institute of Turkmenistan.

\section{Conclusions}

Research work has been carried out in this helium greenhouse and the following results obtained:

1. It has been studied that heating by the usual sun energy can also be said to have shortages and dominance of energy resources during a normal sunny day. In this case, there is a need to adjust the temperature inside the greenhouse.

2. Heat supply was studied at the expense of soil heat in a helium greenhouse filled with horse manure. The soil temperature was maintained at an average temperature of $34-42{ }^{\circ} \mathrm{C}$ for 5 months.

3 . The heating chamber is built in a south-facing direction, and the slope angle of its glass is $36^{\circ}$, that is why it has a large temperature difference from that of the environment. In the research that heat was transferred to the underground part of the greenhouse through the heat pump where were the heat pipes installed. The effect of the temperature on the helium greenhouse was investigated, and $+5{ }^{\circ} \mathrm{C}$ was obtained when the ambient air temperature was $+1{ }^{\circ} \mathrm{C}$ in the morning. It can be said that this method is effective until the temperature drops to minus.

4. The soil temperature of the heating chamber was transferred to the helium greenhouse by heat pump with the help of heat pipelines installed in the underground part, and in the $-2{ }^{\circ} \mathrm{C}$ cold weather the difference was $+6{ }^{0} \mathrm{C}$ in the greenhouse.

5. During the day, the excess heat generated in the helium greenhouse and the heating chamber (goes up to $+52{ }^{\circ} \mathrm{C}$ ) was transferred to the underground mountain rocks and horse manure for the purpose of accumulating heat energy through heat pumps, and in the evening when the temperature in the helium greenhouse decreased the phenomenon reversed.

\section{References}

1. A. Ivanko, A. Kalinechenko, and N. Shmat "Solar Vegetation" Kiev.2004;312

2. D.I.Karas', S.T.Mosin Ispol'zovanie teploty uhodyashchih gazov kotlov dlya teplosnabzheniya teplic. Promyshlennaya energetika, 1988, №5

3. V.A. Kubis Proektirovanie i opyt ekspluatacii energoeffektivnyh teplic (na primere Penzenskoj oblasti) (Monografiya) Penza: PGUAS, 2014. $128 \mathrm{~s}$

4. Banik P,Gangul tA.Performance and economic analysis of a flori cultural greenhouse with distributed fan-pad evaporative cooling coupled with solar desiccation. SolEnergy 2017;147:439-47.

5. Ahmed Solimon, Jerome Adams, and Chris Reidl, Senior Design project: Hybrid Energy Integrator, Drexel University, 2013.

6. Taki M, Ajabshirchi Y, Ranjbar SF, Rohani A, Matloobi M. Heat transfer and MLP neural network models to predict inside environment variables and energy lost in a semi-solargreenhouse. Energy Build 2016;110:314-29. 
7. Kindelam M. Dynamic modeling of greenhouse environment. Trans ASAE 1980;23(5):1232-6.

8. Arinze EA, Schoenau GJ, Besant RW. A dynamic thermal performance simulation model of energy conserving greenhouse with thermal storage. Trans ASAE 1984;27:508-19.

9. Tiwari GN. Analysis of winter greenhouse. Int J Sol Energy 1984;3:19-24.

10. Gupta MJ, Chandra P. Effect of greenhouse design parameters on conservation of energy for greenhouse environmental control. Energy 2002;27:777-94.

11. Their Future Is Green: The Clean-Energy Economy Promises An Engineering Jobs Bounty - Training Graduates With Right Skills, American Society for Engineering Education PRISM, pp. 38-41, 4/2010.

12. Cossu M, Murgia L, Ledda L, Deligios PA, Sirigu A, Chessa F,et al. Solar radiation distribution inside a greenhouse with south-oriented photovoltaic roofs and effects on crop productivity. Appl Energy 2014;133:89-100.

13. Hassan GE,SalahAH, Fath H, ElhelwM,Hassan A, Saqr KM. Optimum operational performance of a new stand-alone agricultural greenhouse with integrated-TPV solar panels. Sol Energy 2016;136:303-16.

14. Dr. Richard Chiou, Drexel University, Dr. Radian G Belu, Drexel University (Tech.) Prototype Design of a Solar Greenhouse Incorporating Clean Energy Manufacturing Concept/ 121 st ASEE Annual Conference \& Exposition/ Indianapolis, IN June 1518,2014

15. K.Saryyev, M.Orazberdiyeva, J.Batmanov. Selfcontained energy saving solar greenhouse. Science and technology journal of Turkmenistan, 2020, №3.

16. Ahmed Solimon, Jerome Adams, and Chris Reidl, Senior Design project: Hybrid Energy Integrator, Drexel University, 2013.

17. P. Jennings, New directions in renewable energy education. International Journal of Renewable Energy, 34, 435-439, 2009.

18. https://asenergi.com/catalog/ventilyatoryac/ventilyator120x120x38/rqa12038hsl220vac.html. 